\title{
Functional Polymers. XVIII. Radical Grafting of 2-(2-Hydroxy-5-vinylphenyl)-2H-benzotriazole onto Polybutadienes ${ }^{\dagger}$
}

\author{
Motozumi KITAYAMA and Otto VoGL
}

Polymer Science and Engineering Department, University of Massachusetts, Amherst, Massachusetts 01003, U.S.A.

(Received January 27, 1982)

\begin{abstract}
Hydroxy-5-vinylphenyl)-2 $H$-benzotriazole was grafted onto two types of butadiene polymers, 1,2-polybutadiene and cis-1,4-polybutadiene, using azobisisobutyronitrile as the initiator. 2-(2-Hydroxy-5-vinylphenyl)- $2 H$-benzotriazole was grafted with a conversion of about $20 \%$, and the efficiency exceeding $50 \%$. The polybutadiene grafting efficiency depended on the structure of the polymer. For 1,2-polybutadiene, the grafting efficiency was $56 \%$, while for cis1,4-polybutadiene it was only $14 \%$. For comparison, 2-(2-hydroxy-5-vinylphenyl)- $\mathrm{H}$-benzotriazole was also homopolymerized, not only with AIBN, but also with benzoyl peroxide as the initiator. In the latter case the yields were relatively low.
\end{abstract}

KEY WORDS 2-(2-Hydroxy-5-vinylphenyl)-2 $H$-benzotriazole / Ultraviolet

Absorbers / Graft Copolymers / Polybutadiene Graft Copolymers / Grafting Efficiency / Radical Grafting / Photostabilizer / Functionalization of Polymers /

2-(2-Hydroxy-5-vinylphenyl)-2H-benzotriazole $(2 \mathrm{H} 5 \mathrm{~V})$ is an efficient, polymerizable ultraviolet stabilizer. ${ }^{1-4}$ It is easily synthesized, polymerized, and also grafted onto aliphatic polymers. ${ }^{5}$ Grafting of monomers which introduced functionality into polymers has been used in the past; these functionalities include antioxidants and, most recently, ultraviolet stabilizing compounds. ${ }^{6}$ It was found that methyl 5-vinylsalicylate can be readily grafted onto polymers with unsaturated groups. The polymer backbones chosen were two types of polybutadienes: a) 1,2-polybutadiene (1,2-PBD) and b) cis-1,4-polybutadiene (cis-1,4-PBD). Benzoyl peroxide (BPO) or azobisisobutyronitrile (AIBN) were

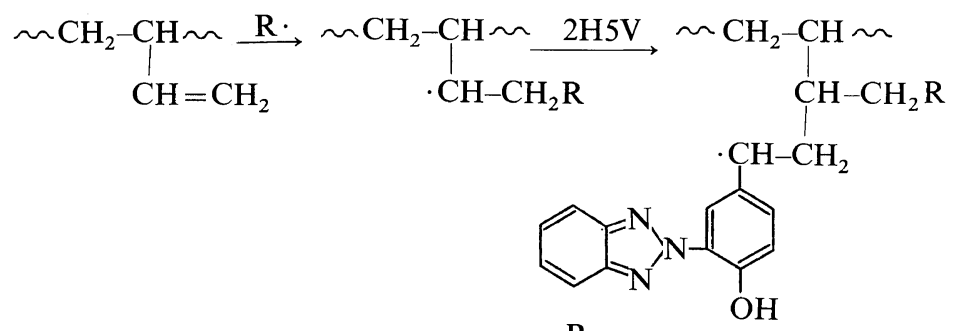

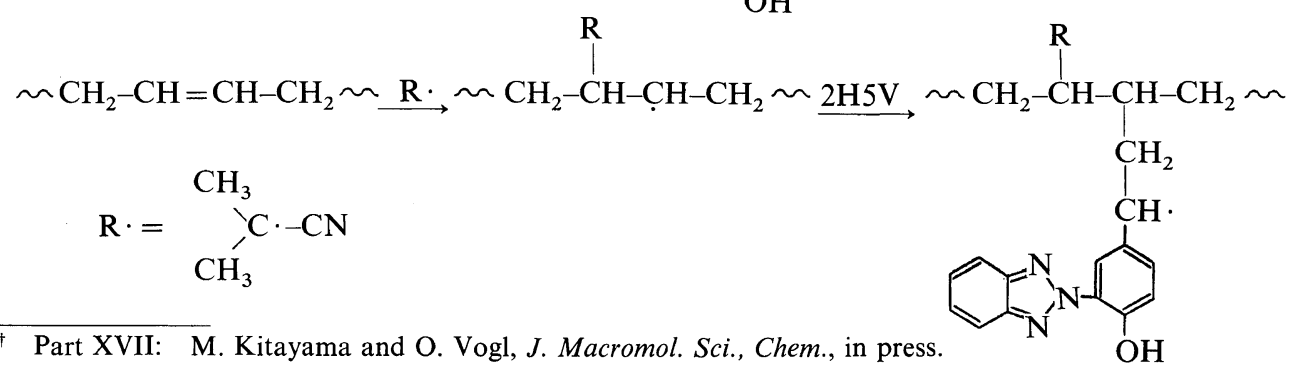


used as the grafting initiators. It was shown that grafting occurs readily, with the grafting efficiency ranging from $23 \%$ to $65 \%$, depending on the reaction conditions.

We have continued our efforts in developing general methods for the functionalization of polymers and in this paper report further functionalization of polybutadienes by grafting $2 \mathrm{H} 5 \mathrm{~V}$ onto the 1,2- and cis-1,4-isomer of polybutadiene with AIBN as the initiator. The following reaction scheme suggests a possible mechanism for the freeradical grafting of $2 \mathrm{H} 5 \mathrm{~V}$ onto $1,2-\mathrm{PBD}$ and $c i s-1,4-$ PBD, initiated with AIBN (eq 1).

\section{EXPERIMENTAL}

\section{Materials}

Methanol, acetone, petroleum ether, chloroform, and toluene (Fisher Scientific Co.) were distilled at atmospheric pressure. Benzene (Fisher Scientific Co.) was washed with sulfuric acid, aqueous sodium hydroxide solution, water, and dried over phosphorous pentoxide before distillation.

Azobisisobutyronitrile (AIBN) (Eastman Kodak Co.) and benzoyl peroxide (BPO) (Fisher Scientific Co.) were recrystallized and dried at $0.1 \mathrm{mmHg}$ and room temperature.

cis-1,4-Polybutadiene (Japan Synthetic Rubber Co.) (BR-01) had the following compositon: cis-1,4$(97.5 \%)$; trans-1,4- $(1.2 \%)$; 1.2 - $(1.3 \%) ; 1.2$-polybutadiene (BR-820) consisted of $1,2-(92 \%)$; cis-1,4$(8 \%)$. Both polybutadienes (PBD) were purified by being dissolved in benzene, filtering, precipitation of the polymer solution into methanol, filtering the suspension, and drying the polymer over phosphorous pentoxide at $0.1 \mathrm{~mm}$.

2-(2-Hydroxy-5-vinylphenyl)-2H-benzotriazole $(2 \mathrm{H} 5 \mathrm{~V})$ was synthesized in this laboratory ${ }^{4}$ and purified before use. 2,2'-Methylenebis(6-tert-butyl$p$-cresol) (MBC) (Pfaltz \& Bauer, Inc.) was used as received.

\section{Measurements}

Infrared spectra were recorded on a Perkin-Elmer spectrometer, model 727 or 283 , in the form of films cast from chloroform solution.

${ }^{1} \mathrm{H}$ and ${ }^{13} \mathrm{C}$ NMR spectra were measured in $10 \%$ or $15 \%$ deuterated chloroform (Norell Co., Inc.) solutions on a $60 \mathrm{MHz}$ Varian T-60 and a Varian CFT-20 spectrometer, respectively.
A Perkin-Elmer differential scanning calorimeter (DSC-2) was used for the determination of glass transition temperatures $\left(T_{\mathrm{g}}\right)$ and thermal behavior of the polymers. DSC scans were recorded at a rate of temperature increase of $20^{\circ} \mathrm{C} \mathrm{min}^{-1}$ with sample sizes of $6-7 \mathrm{mg}$. The temperature at which one-half of the $\Delta C_{\mathrm{p}}$ transition was noted was registered as the $T_{\mathrm{g}}$.

\section{Procedures}

Homopolymerization of 2-(2-Hydroxy-5-vinylphenyl)-2H-benzotriazole (2H5V). Polymerization of $2 \mathrm{H} 5 \mathrm{~V}$ was carried out with $\mathrm{BPO}$ as the initiator. A $15 \mathrm{ml}$ polymerization tube was charged with BPO $(3.5 \mathrm{mg}, 0.014 \mathrm{mmol}), 0.5 \mathrm{~mol} \%$, $2 \mathrm{H} 5 \mathrm{~V}(0.66 \mathrm{~g}, 2.8 \mathrm{mmol})$, and benzene $(7 \mathrm{ml})$. The homogeneous mixture was degassed, sealed at $0.05 \mathrm{~mm}$, and placed in a constant temperature bath of $60^{\circ} \mathrm{C}$ for 3 days. The homogeneous solution was poured into cold methanol $(200 \mathrm{ml})$, the polymer precipitated and was collected on a sintered glass filter, washed and dried at $0.1 \mathrm{mmHg}$; poly $(2 \mathrm{H} 5 \mathrm{~V})$ $(0.086 \mathrm{~g})(13 \%$ yield $)$ was obtained.

This polymer was identical in every respect with the polymer obtained by polymerization of $2 \mathrm{H} 5 \mathrm{~V}$ with AIBN as the initiator and which gave a $51 \%$ yield of poly $(2 \mathrm{H} 5 \mathrm{~V})$.

Grafting Procedures.

Grafting of $2 \mathrm{H} 5 \mathrm{~V}$ onto cis-1,4-PBD (BR-01) with $A I B N$ as the grafting initiator. BR-01 $(1.35 \mathrm{~g}, 25$ monomer mmol) was dissolved in benzene $(45 \mathrm{ml})$ under dry nitrogen in a $100 \mathrm{ml}$ polymerization tube. $2 \mathrm{H} 5 \mathrm{~V}(1.78 \mathrm{~g}, 7.5 \mathrm{mmol})$ and AIBN $(3.3 \mathrm{mg}, 0.020$ $\mathrm{mmol}), 0.06 \mathrm{~mol} \%$, were then added, followed by benzene $(5 \mathrm{ml})$. The homogeneous mixture was degassed, sealed at $0.05 \mathrm{~mm}$ and heated to $60^{\circ} \mathrm{C}$ for three days. The tube was opened and the homogeneous contents were poured into cold methanol $(500 \mathrm{ml})$. The precipitated polymer was collected and purified by a careful separation procedure (see below). From the weight of the total polymer and the weight of BR-01 initially present, the amount of $2 \mathrm{H} 5 \mathrm{~V}$ polymerized was calculated as $0.28 \mathrm{~g},(16 \%$ conversion).

Grafting onto 1,2-PBD (BR 820) was carried out in a similar manner and resulted in a $23 \%$ conversion of $2 \mathrm{H} 5 \mathrm{~V}$ to polymers.

Separation of Polymers. 2H5V homopolymer $[$ poly $(2 \mathrm{H} 5 \mathrm{~V})]$ and residual polybutadiene (PBD) were extracted from the mixture of polymers by 
leaching them repeatedly with alternative cold solvents. The total polymer, cut into small pieces, was placed in a weighed Soxhlet thimble. First, the unchanged PBD was extracted by shaking the mixture mechanically in the dark at room temperature for at least 2 days with $100 \mathrm{ml}$ of petroleum ether (bp $40-60^{\circ} \mathrm{C}$ ) containing $2 \%$ of $2,2^{\prime}$-methylenebis $(6-$ tert-butyl-p-cresol) (MBC) as an antioxidant. The extract was concentrated to $10 \mathrm{ml}$ and poured into methanol $(100 \mathrm{ml})$. The precipitated polymer was collected in a weighed, sintered glass filter, washed and dried at $0.1 \mathrm{~mm}$ to a constant weight. Poly $(2 \mathrm{H} 5 \mathrm{~V})$ was then extracted by shaking the thimble in $100 \mathrm{ml}$ of a $2 \%$ solution of $\mathrm{MBC}$ in acetone in the dark at room temperature for a minimum of 2 days. The extracted poly $(2 \mathrm{H} 5 \mathrm{~V})$ was recovered in the same manner as PBD. Both extractions were repeated until no more polymer could be detected in the extracts. The remaining graft copolymer [poly(BD- $g-2 \mathrm{H} 5 \mathrm{~V})]$ was isolated by repeated thimble extractions with $100 \mathrm{ml}$ of toluene (containing $2 \%$ of $\mathrm{MBC}$ ) in the dark at room temperature as described above. About ten extractions were required to obtain a pure graft copolymer.

Infrared spectra revealed that both fractions, the petroleum extract containing $\mathrm{PBD}$ and the acetone extract containing poly $(2 \mathrm{H} 5 \mathrm{~V})$, were contaminated with a small amount of graft copolymer.

2H5V could be grafted onto both PBD's, 1,2PBD and $c i s-1,4-\mathrm{PBD}$ with AIBN as the initiator.

Poly(1,4-BD-g-2H5V)

Anal. Found: C, $80.68 \%$; H, $8.36 \%$; N, $8.04 \%$. Calcd for $\left(-\mathrm{C}_{4} \mathrm{H}_{6}\right)_{0.84}\left(\mathrm{C}_{14} \mathrm{H}_{11} \mathrm{~N}_{3} \mathrm{O}\right)_{0.16}$ : C, $80.66 \%$; $\mathrm{H}, 8.21 \%$; N, $8.06 \%$.

Poly(2,2-BD- $g$-2H5V).

Anal. Found: C, $82.34 \%$; H, 9.66\%; N, $4.16 \%$. Calcd for $\left(\mathrm{C}_{4} \mathrm{H}_{6}\right)_{0.93}\left(\mathrm{C}_{14} \mathrm{H}_{11} \mathrm{~N}_{3} \mathrm{O}\right)_{0.07}: \mathrm{C}, 84.29 \%$; $\mathrm{H}, 9.65 \% ; \mathrm{N}, 4.39 \%$.

\section{RESULTS AND DISCUSSION}

Grafting of $2 \mathrm{H} 5 \mathrm{~V}$ was carried out with AIBN as

Table I. Experimental conditions for graft- and homo-polymerizations ${ }^{\mathrm{a}}$

\begin{tabular}{|c|c|c|c|c|c|c|}
\hline \multirow{2}{*}{$\begin{array}{l}\text { PBD } \\
\text { type }\end{array}$} & \multirow{2}{*}{$\frac{\text { PBD concentration }}{\text { monomer mol } 1^{-1}}$} & \multirow{2}{*}{ Initiator } & \multicolumn{2}{|c|}{$\begin{array}{c}\text { Initiator } \\
\text { concentration }\end{array}$} & \multicolumn{2}{|c|}{$\begin{array}{c}\text { Monomer } 2 \mathrm{H} 5 \mathrm{~V} \\
\text { concentration }\end{array}$} \\
\hline & & & $\mathrm{mmol} \mathrm{1}^{-1}$ & $\mathrm{~mol} \%$ & $\mathrm{~mol} \mathrm{1} 1^{-1}$ & $\mathrm{~mol} \%$ \\
\hline $1,2-$ & 0.42 & AIBN & 0.33 & 0.06 & 0.13 & 23 \\
\hline$c i s-1,4$ & 0.50 & AIBN & 0.40 & 0.06 & 0.15 & 23 \\
\hline - & - & AIBN & 2.0 & 0.5 & 0.40 & 100 \\
\hline - & - & BPO & 2.0 & 0.5 & 0.40 & 100 \\
\hline
\end{tabular}

a Temperature, $60^{\circ} \mathrm{C}$; time, 3 days; solvent, benzene.

Table II. Results of graft- and homo-polymerization

\begin{tabular}{|c|c|c|c|c|c|}
\hline \multirow{3}{*}{$\begin{array}{l}\text { PBD } \\
\text { type }\end{array}$} & \multirow{3}{*}{$\begin{array}{c}\begin{array}{c}2 \mathrm{H} 5 \mathrm{~V} \\
\text { conversion }\end{array} \\
\%\end{array}$} & \multirow{3}{*}{$\begin{array}{c}\begin{array}{c}\text { Poly(2H5V) } \\
\text { grafting } \\
\text { efficiency }\end{array} \\
\%\end{array}$} & \multirow{3}{*}{$\begin{array}{c}\begin{array}{c}\text { PBD } \\
\text { grafting } \\
\text { efficiency }\end{array} \\
\%\end{array}$} & \multicolumn{2}{|c|}{$\operatorname{Poly}(2 \mathrm{H} 5 \mathrm{~V})$ content in poly (BD- $g-2 \mathrm{H} 5 \mathrm{~V})$} \\
\hline & & & & \multirow[t]{2}{*}{$\mathrm{mol} \%$} & \multirow{2}{*}{$\mathrm{wt} \%$} \\
\hline & & & & & \\
\hline $1,2-$ & 23 & 56 & 56 & 7 & 23 \\
\hline cis-1,4- & 16 & 51 & 13 & 16 & 45 \\
\hline- & $51(\mathrm{AIBN})$ & - & - & - & - \\
\hline- & $13(\mathrm{BPO})$ & - & - & - & - \\
\hline
\end{tabular}

a $\quad$ Poly $(2 \mathrm{H} 5 \mathrm{~V})$ grafting efficiency $=\frac{\text { wt of poly }(2 \mathrm{H} 5 \mathrm{~V}) \text { included in graft polymer }}{\text { Total wt of poly }(2 \mathrm{H} 5 \mathrm{~V})} \times 100$.

b PBD grafting efficiency $=\frac{\text { wt of PBD included in graft polymer }}{\text { Original wt of PBD }} \times 100$. 
M. KitAyama and O. VogL

Table III. ${ }^{1} \mathrm{H}$ NMR chemical shift data of poly(BD- $\left.g-2 \mathrm{H} 5 \mathrm{~V}\right)^{\mathrm{a}}$

\begin{tabular}{ccccc}
\hline Sample & $-\mathrm{OH}$ & $\begin{array}{c}\text { Benzene } \\
\text { ring }\end{array}$ & $\begin{array}{c}-\mathrm{CH}=(1,2-\mathrm{PBD} \\
\text { and } c i s-1,4-\mathrm{PBD}) \\
=\mathrm{CH}_{2}(1,2-\mathrm{PBD})\end{array}$ & $\begin{array}{l}-\mathrm{CH}_{2}-[\mathrm{cis}-1,4-\text { and } 1,2-\mathrm{PBD} \\
\text { and poly(2H5V)] } \\
-\mathrm{CH}-[(1,2-\mathrm{PBD} \text { and poly(2H5V)] }\end{array}$ \\
\hline Poly(BD-g-2H5V) & $10.5-11.0$ & $6.4-8.5$ & $4.4-6.0$ & $0.8-3.0$ \\
\hline
\end{tabular}

a In $\mathrm{CDCl}_{3}(15 \%), 25^{\circ} \mathrm{C}$.

the grafting initiator onto both, 1,2- and cis-1,4$\mathrm{PBD}$. The homopolymerization of $2 \mathrm{H} 5 \mathrm{~V}$ was also performed with either AIBN or BPO as the initiator to give poly $(2 \mathrm{H} 5 \mathrm{~V})$ in a $51 \%$ yield with AIBN and in a $13 \%$ yield with BPO. Beacuse of its greater efficiency in homopolymerization, AIBN was used for the grafting of $2 \mathrm{H} 5 \mathrm{~V}$ onto $1,2-$ or cis-1,4-PBD.

As described for the grafting of methyl 5-vinylsalicylate, ${ }^{6}$ the amount of initiator and the grafting conditions have to be carefully controlled in order to avoid crosslinking. These conditions were also very carefully followed in our grafting experiments of $2 \mathrm{H} 5 \mathrm{~V}$ onto the two PBD's. The initiator concentration for the grafting reaction was usually 0.06 $\mathrm{mol} \%$. The experimental conditions of the polymerization and grafting reactions are summarized in Table I and the results in Table II. In the case of grafting of $2 \mathrm{H} 5 \mathrm{~V}$ onto $1,2-\mathrm{PBD}$, a $23 \%$ conversion of $2 \mathrm{H} 5 \mathrm{~V}$ to the polymer was achieved, with $56 \%$ of the $2 \mathrm{H} 5 \mathrm{~V}$ grafted and $44 \%$ of it homopolymerized. The grafting efficiency onto PBD, the utilization of $\mathrm{PBD}$ in the grafting reaction, was also $56 \%$. For the grafting reaction onto $c i s-1,4-\mathrm{PBD}$, the conversion of $2 \mathrm{H} 5 \mathrm{~V}$ was only $16 \%$, with a poly $(2 \mathrm{H} 5 \mathrm{~V})$ grafting efficiency and a PBD grafting efficiency of $51 \%$ and $13 \%$, respectively. As a result, the poly $(2 \mathrm{H} 5 \mathrm{~V})$ content in poly(BD-g-2H5V) was $7 \mathrm{~mol} \%$ for $1,2-$ PBD and $16 \mathrm{~mol}^{\circ} \%$ for the cis-1,4-PBD. The chemical shift data of both ${ }^{1} \mathrm{H}$ and ${ }^{13} \mathrm{C}$ NMR spectra of poly(BD-g-2H5V) (Tables III and IV) confirm the proposed structures as do the elemental analyses, especially the nitrogen analyses. In our polymer samples, the molecular weight of the PBD backbone was high, causing a broadening in the ${ }^{1} \mathrm{H}$ NMR spectrum and requiring many transients in the ${ }^{13} \mathrm{C}$ NMR spectrum. The proton signals due to the $2 \mathrm{H} 5 \mathrm{~V}$ moiety in the copolymer were weak relative to the proton signals due to the hydrocarbon backbone and their intensity ratios appeared to be consistent with the copolymer composition as calculated on the basis of the elemental analyses.
Table IV. ${ }^{13} \mathrm{C}$ NMR chemical shift data for poly(BD- $g-2 \mathrm{H} 5 \mathrm{~V})^{\mathrm{a}}$

\begin{tabular}{|c|c|c|}
\hline $\begin{array}{l}\text { Poly } 2 \mathrm{H} 5 \mathrm{~V} \text { in } \\
\text { poly(BD-g-2H5V) }\end{array}$ & $\begin{array}{l}\text { Chemical shift } \\
\text { (ppm downfield } \\
\text { from TMS) }\end{array}$ & Assignment \\
\hline$\sim \stackrel{\mathrm{CH}}{\mathrm{C}}$ & $\begin{array}{r}147.6 \\
142.1 \\
135.4 \\
129.0 \\
127.0 \\
125.2 \\
119.8 \\
118.9 \\
117.3\end{array}$ & $\begin{array}{l}\mathrm{g} \\
\mathrm{a} \\
\mathrm{d} \\
\mathrm{c} \\
\mathrm{i} \\
\mathrm{f} \\
\mathrm{e} \\
\mathrm{b} \\
\mathrm{h}\end{array}$ \\
\hline 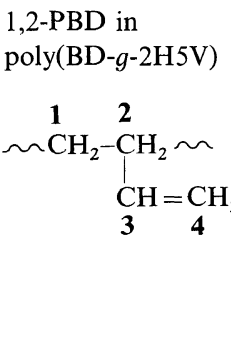 & $\begin{array}{r}142.9 \\
130.6 \\
127.6 \\
114.8 \\
114.4 \\
41.4 \\
38.8 \\
35.7 \\
27.4 \\
25.0\end{array}$ & $\begin{array}{l}3 \\
3 \\
3 \\
4^{\mathrm{b}} \\
4^{\mathrm{c}} \\
2 \\
1 \\
1 \\
1 \\
1\end{array}$ \\
\hline $\begin{array}{l}c i s-1,4-\mathrm{PBD} \text { in } \\
\text { poly(BD-g-2H5V) }\end{array}$ & $\begin{array}{r}129.6 \\
27.5\end{array}$ & $\begin{array}{l}-\mathrm{CH}= \\
-\mathrm{CH}_{2}-\end{array}$ \\
\hline
\end{tabular}

a In $\mathrm{CDCl}_{3}(10 \%), 25^{\circ} \mathrm{C}$.

b Syndiotactic triads.

c Heterotactic triads.

However, the best indication of the incorporation of $2 \mathrm{H} 5 \mathrm{~V}$ were the infrared spectra (Figures 1 and 2) where the phenolic $\mathrm{OH}$-absorption band of $2 \mathrm{H} 5 \mathrm{~V}$ is easily recognized at $3200 \mathrm{~cm}^{-1}$.

Preliminary thermal characterization of our graft copolymers of 1,2-PBD and cis-1,4-PBD with 2H5V were carried out by DSC. Only one $T_{\mathrm{g}}$ was found for each of the graft polymers: a $T_{\mathrm{g}}$ of $-10^{\circ} \mathrm{C}(1,2-$ $\mathrm{PBD})$ and $-107^{\circ} \mathrm{C}$ (cis-1,4-PBD) which correspond to the $T_{\mathrm{g}}$ for pure $1,2-\mathrm{PBD}\left(-10^{\circ} \mathrm{C}, 263 \mathrm{~K}\right)$ and cis- 
Functional Polymers. XVIII.

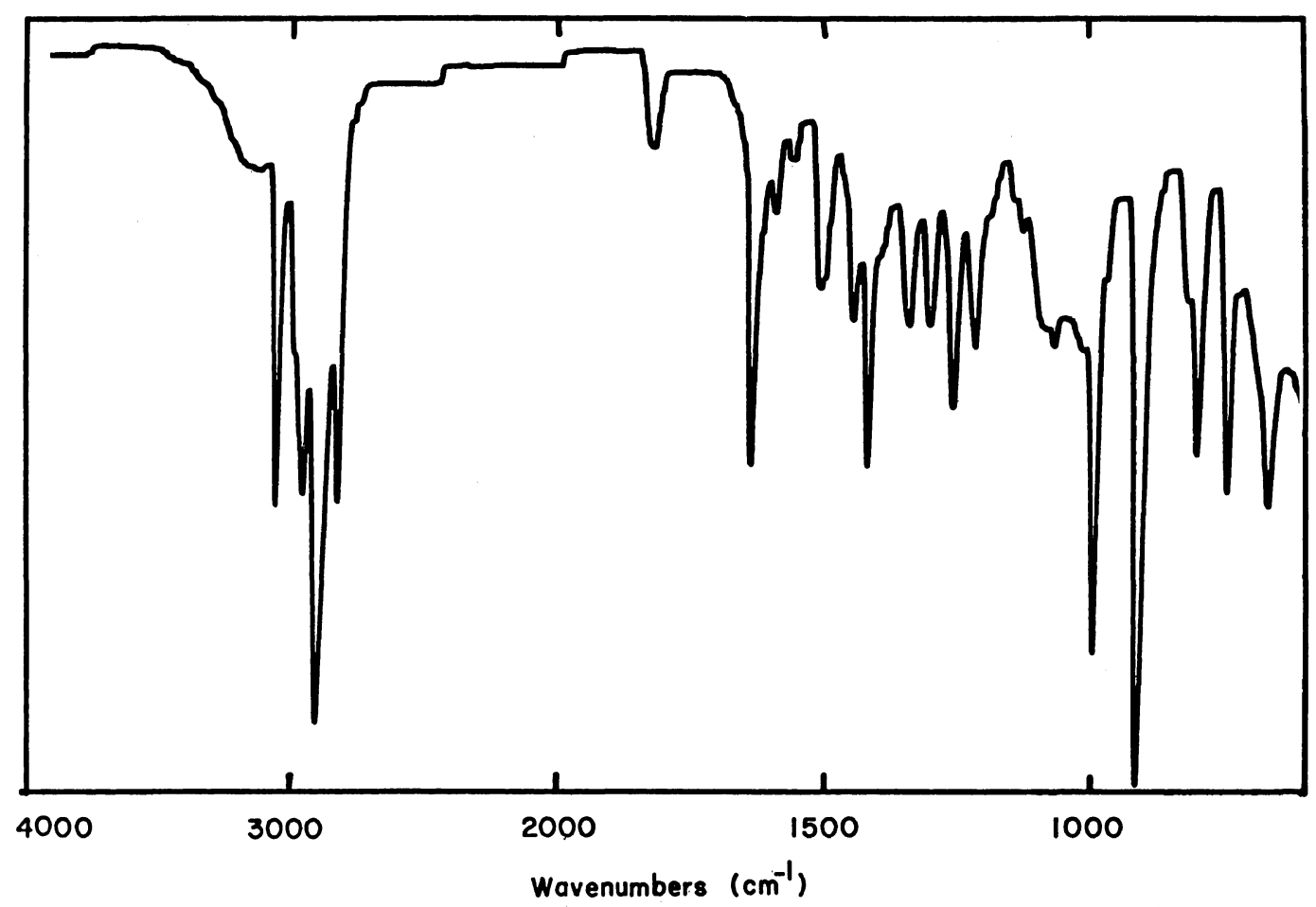

Figure 1. Infrared spectrum of poly(BD-g-2H5V) (1,2-PBD).

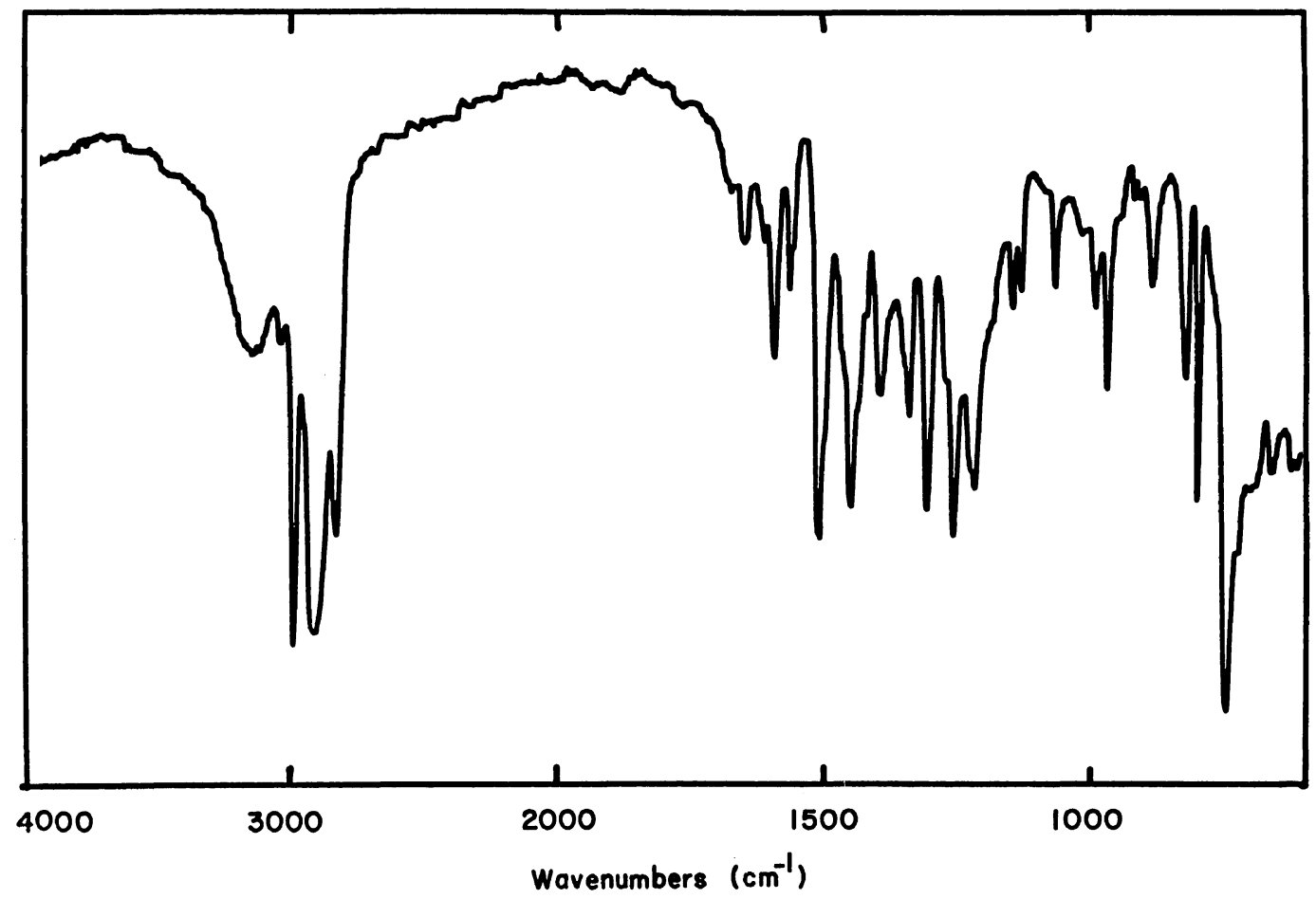

Figure 2. Infrared spectrum of poly(BD-g-2H5V) (cis-1,4-PBD). 
1,4-PBD $\left(-108^{\circ} \mathrm{C}, 165 \mathrm{~K}\right)$, respectively. No $T_{\mathrm{g}}$ was found at $109^{\circ} \mathrm{C}(402 \mathrm{~K})$ which is the $T_{\mathrm{g}}$ of poly $(2 \mathrm{H} 5 \mathrm{~V})$ (Table V). This $T_{\mathrm{g}}$ would be difficult to observe, possibly because the poly $(2 \mathrm{H} 5 \mathrm{~V})$ units are present as short chains only. If so, they would not form a separate $2 \mathrm{H} 5 \mathrm{~V}$-phase and hence no separate glass transition could be observed.

Blends of PBD with poly $(2 \mathrm{H} 5 \mathrm{~V})$ and poly(BD- $g$ $2 \mathrm{H} 5 \mathrm{~V}$ ) showed only the $T_{\mathrm{g}} \mathrm{s}$ corresponding to the pure PBDs. A $T_{\mathrm{g}}$ at $109^{\circ} \mathrm{C}(402 \mathrm{~K})$, corresponding to poly $(2 \mathrm{H} 5 \mathrm{~V})$, was observed only in the case of the highest concentration of poly $(2 \mathrm{H} 5 \mathrm{~V})$ in the blend $(68 \mathrm{wt} \%)$ (Table VI).

We compared also the DSC scans of the graft copolymers of poly(BD-g-2H5V) with those of blends of PBD with poly $(2 \mathrm{H} 5 \mathrm{~V})$. The blends contained the same amounts of PBD and poly $(2 \mathrm{H} 5 \mathrm{~V})$ as the corresponding graft copolymers (Figure 3). The peak areas due to crystallization and melting are smaller in the graft copolymers than in the corresponding blends. This seems to indi- cate a short graft length of the grafted poly$(2 \mathrm{H} 5 \mathrm{~V})$ and consequently no efficient compatibilization between the incompatible homopolymers

Table V. DSC ${ }^{\text {a }}$ data for transition temperatures of poly(BD- $g-2 \mathrm{H} 5 \mathrm{~V})$

\begin{tabular}{|c|c|c|c|c|}
\hline \multirow{2}{*}{ Sample } & \multicolumn{2}{|c|}{$T_{\mathrm{g}}^{\mathrm{b}}$} & \multirow{2}{*}{$\frac{T_{\mathrm{cr}}^{\mathrm{c}}}{\mathrm{K}}$} & \multirow{2}{*}{$\frac{T_{\mathrm{m}}^{\mathrm{d}}}{\mathrm{K}}$} \\
\hline & & r & & \\
\hline Poly(2H5V) & - & 402 & & \\
\hline \multicolumn{5}{|l|}{ 1,2-PBD: } \\
\hline Original polymer & 263 & - & & \\
\hline Graft polymer & 263 & - & - & - \\
\hline \multicolumn{5}{|l|}{$c i s-1,4-\mathrm{PBD}:$} \\
\hline Original polymer & 165 & - & 204 & 261 \\
\hline Graft polymer & 166 & - & 207 & 269 \\
\hline
\end{tabular}

a Scanning rate, $20^{\circ} \mathrm{C} \min ^{-1}$.

${ }^{\mathrm{b}}$ Glass transition temperature (one half of $\Delta C_{\mathrm{p}}$ of transition).

c Temperature of crystallization (peak temperature).

d Melting temperature (peak temperature).

Table VI. DSC data for transition temperature of blends

\begin{tabular}{|c|c|c|c|c|c|}
\hline \multicolumn{3}{|c|}{ Blend compositions, in proportions by weight } & $\frac{T_{\mathrm{g}}}{\mathrm{K}}$ & $\begin{array}{c}T_{\mathrm{cr}} \\
\mathrm{K}\end{array}$ & $\frac{T_{\mathrm{m}}}{\mathrm{K}}$ \\
\hline 1,2-PBD & Poly $(2 \mathrm{H} 5 \mathrm{~V})$ & Poly(BD-g-2H5V) & & & \\
\hline $\begin{array}{c}77 \\
c i s-1,4-\mathrm{PBD}\end{array}$ & $\begin{array}{c}23 \\
\text { Poly }(2 \mathrm{H} 5 \mathrm{~V})\end{array}$ & Poly(BD-g-2H5V) & $262-$ & - & - \\
\hline 55 & 45 & - & $166-$ & 212 & 262 \\
\hline 25 & 75 & 10 & 166,404 & 216 & 260 \\
\hline 55 & 45 & 10 & $166-$ & 214 & 261 \\
\hline 75 & 25 & 10 & $166-$ & 210 & 262 \\
\hline
\end{tabular}

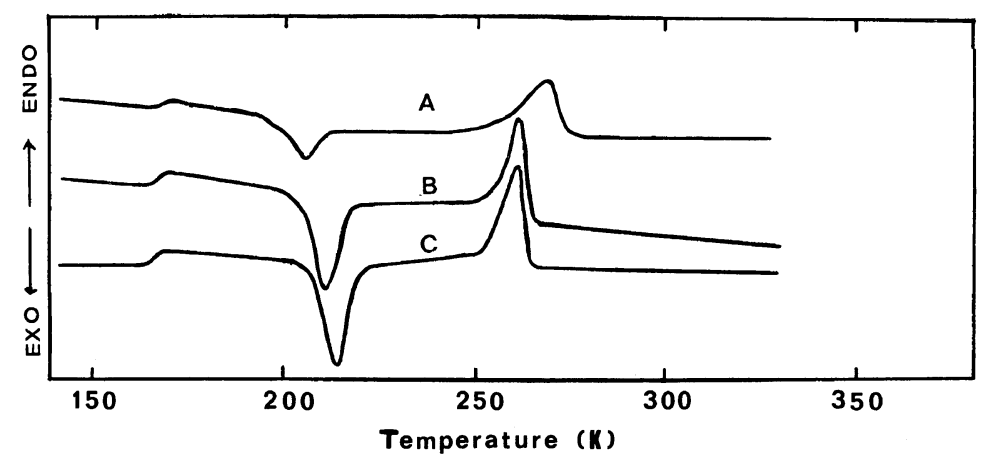

Figure 3. DSC scans of poly(BD- $g-2 \mathrm{H} 5 \mathrm{~V})$ and of blends: $\mathrm{A}$, poly $(\mathrm{BD}-\mathrm{g}-2 \mathrm{H} 5 \mathrm{~V}) ;[55 \%$ (wt) of cis-1,4$\mathrm{PBD}$ in poly(BD-g-2H5V)]; B, blend of cis-1,4-PBD/poly(2H5V) $(55: 45 \mathrm{wt} / \mathrm{wt})$; C, blend of cis-1,4$\mathrm{PBD} /$ poly $(2 \mathrm{H} 5 \mathrm{~V}) /$ poly(BD-g-2H5V); (55: $45: 10 \mathrm{wt} / \mathrm{wt} / \mathrm{wt})$. 
PBD and poly $(2 \mathrm{H} 5 \mathrm{~V})$ was achieved in the graft copolymer.

Acknowledgements. This work was supported by the Bridgestone Tire Company Ltd., Tokyo, Japan and in part by a grant from the National Science Foundation to the Materials Research Laboratory at the University of Massachusetts. $2 \mathrm{H} 5 \mathrm{~V}$ was synthesized by S. Yoshida. M.K. would like to express his appreciation to the Bridgestone Tire Company, Ltd. for granting a two-year leave of absence to work at the University of Massachusetts.

We would like to thank William J. Harris and Paula Loeffler for their assistance in the preparation of this manuscript.

\section{REFERENCES}

1. S. Yoshida and O. Vogl, Polym. Prepr., Am. Chem. Soc. Div. Polym. Chem., 21, 201 (1980).

2. O. Vogl and S. Yoshida, Preprints, Annual Meeting, Society of Polymer Science, Kyoto, 1980, 29, 648 (1980).

3. S. Yoshida and O. Vogl, Makromol. Chem., 183, 259 (1982).

4. O. Vogl and S. Yoshida, Rev. Roum. Chim., 7, 1123 (1980).

5. W. Pradellok, A. Gupta, and O. Vogl, J. Polym. Sci., Polym. Chem. Ed., 19, 3307 (1981).

6. M. Kitayama and O. Vogl, J. Macromol. Sci., Polym. Chem., in press.

7. H. Kawaguchi, J. Muggee, and O. Vogl, Polymer (London), in press. 